\title{
ACADEMIC BUOYANCY PADA MAHASISWA YANG BEKERJA DAN TIDAK BEKERJA DI JAKARTA
}

\author{
Cristina Hiunata ${ }^{1)}$, Linda $^{2)}$ \\ Program Studi Psikologi Universitas Bunda Mulia, Jakarta \\ ${ }^{1)}$ cristina.hiu95@gmail.com, ${ }^{2}$ 0330linda.wu@gmail.com
}

\begin{abstract}
This research was conducted to test college students' academic buoyancy, especially working college students and not working college students in Jakarta. Academic bouyancy is the ability of students (in this research is college students) to successfully overcome obstacles and problems that occur in everyday academic life, such as facing tasks and examinations from various subjects intended to measure their abilities (Martin \& Marsh in Tarbetsky, Martin \& Collie, 2017). Using independent sample of comparative study with quantitative method to understand the differences of academic buoyancy in working college students and not working college students in Jakarta. Data is gathered by using academic buoyancy questionnaire made by researcher based on Martin \& Marsh (2010) aspect of academic buoyancy. Academic buoyancy questionnaire validity score range from 0.291 to 0.676 and the reliability score is 0.920. Questionnaire is given to 388 college students in Jakarta. Result shows that there are differences between working college students' and not working college students' academic buoyancy in Jakarta. The differences of academic buoyancy is explained by the differences on its aspect, self-efficacy, planning, persistence, and anxiety. Working college students' and not working college students' academic buoyancy are both high in categorization, but working college students' mean are higher than not working college students' mean. For college students who work can reduce anxiety by setting aside a few minutes every day to calm down and make a priority scale to solve important and urgent things first. For college students who are not working, they are expected to make a learning plan in detail and make a target value that is in accordance with their own abilities.
\end{abstract}

Keywords: academic buoyancy, college student, working, not working

ABSTRAK: Penelitian ini dilakukan untuk menguji academic bouyancy pada mahasiswa khususnya mahasiswa yang bekerja dan tidak bekerja di Jakarta. Academic bouyancy adalah kemampuan siswa (dalam penelitian ini adalah mahasiswa) untuk berhasil mengatasi hambatan dan masalah yang terjadi dalam kehidupan akademik sehari-hari, seperti menghadapi tugas-tugas dan ujian dari berbagai mata pelajaran yang dimaksudkan untuk mengukur kemampuan yang dimiliki (Martin \& Marsh dalam Tarbetsky, Martin \& Collie, 2017). Jenis penelitian yang digunakan adalah penelitian komparatif sampel independen dengan metode kuantitatif untuk mengetahui perbedaan academic buoyancy yang dimiliki oleh mahasiswa bekerja dan tidak bekerja di Jakarta. Pengumpulan data dilakukan dengan menggunakan kuesioner academic buoyancy yang disusun oleh peneliti berdasarkan aspek yang dikemukakan oleh Martin \& Marsh (2010). Dari hasil uji coba terhadap kuesioner yang disusun peneliti didapatkan rentang validitas sebesar 0.2910.676 dan nilai reliabilitas sebesar 0.920 . Kuesioner penelitian dibagikan kepada 388 mahasiswa di Jakarta secara secara langsung dan daring. Hasil penelitian menunjukkan bahwa terdapat perbedaan academic buoyancy pada mahasiswa bekerja dan tidak bekerja di Jakarta. Perbedaan juga terlihat pada aspek selfefficacy, planning, persistence, dan anxiety. Academic buoyancy pada mahasiswa bekerja dan tidak bekerja berada pada kategori yang tinggi dengan nilai rata-rata mahasiswa bekerja lebih tinggi daripada nilai ratarata mahasiswa tidak bekerja. Untuk mahasiswa yang bekerja dapat mengurangi kecemasan yang dirasakan dengan menyisihkan beberapa menit setiap hari untuk menenangkan diri dan membuat skala prioritas untuk menyelesaikan hal yang penting dan mendesak terleboh dahulu. Bagi mahasiswa yang tidak bekerja, diharapkan untuk membuat rencana belajar dengan detil dan membuat target nilai yang sesuai dengan kemampuan diri sendiri.

Kata kunci: academic buoyancy, mahasiswa, bekerja, tidak bekerja 


\section{PENDAHULUAN}

Organisasi Kerjasama Ekonomi dan Pengembangan (OECD) menyatakan pada tahun 2020, Indonesia akan menjadi Negara dengan jumlah sarjana muda terbanyak kelima di dunia (Mohamad, 2012). Survei yang dilakukan MasterCard Worldwide menunjukkan kesadaran akan pentingnya pendidikan di kalangan generasi muda Indonesia meningkat, sebagian besar responden yang berencana untuk melanjutkan pendidikan akan membiayai pendidikan menggunakan dana pribadi (Sutriyanto, 2012). Studi yang dilakukan di AS menemukan bahwa individu dengan pendidikan tinggi memiliki kesempatan lebih besar untuk mengakses pekerjaan yang lebih aman dan status yang lebih tinggi (Pendidikan tinggi masih..., 2013).

Jakarta sebagai Ibukota Indonesia terkenal sebagai tempat terbaik untuk mencari kerja karena banyaknya perusahaan-perusahaan besar yang menawarkan gaji tinggi (Iswahyudi, 2015). Pada kenyataannya, biaya hidup di Jakarta lebih tinggi daripada upah minimum provinsi (UMP) yang ditawarkan sehingga banyak karyawan Jakarta yang biaya hidupnya terbantu dari pekerjaan sampingan maupun dibantu oleh orang tua (Syaaf \& Wibawa, 2017). Dengan tingginya biaya hidup di Ibukota Jakarta, berbagai cara dilakukan untuk dapat bertahan hidup (Agustina, 2014). Salah satunya adalah dengan mencari pekerjaan tambahan berupa pekerjaan sambilan.

Di Indonesia pekerjaan sambilan lebih banyak dilakukan oleh pelajar baik SMA maupun mahasiswa (Erasiana, 2017). Mahasiswa menurut Sarwono adalah orang yang terdaftar aktif di sebuah perguruan tinggi (Zamhari, 2016). Mahasiswa yang berada pada masa transisi dari remaja menuju dewasa berada pada tahap eksplorasi identitas dan memiliki kemungkinan untuk mengarahkan kehidupannya ke arah yang lebih baik (Santrock, 2011). Salah satu bentuk eksplorasi identitas yang dilakukan adalah dengan mengikuti berbagai kegiatan seperti berorganisasi atau bekerja sambilan.
Menurut Arnet (dalam Santrock, 2011) transisi dari masa remaja ke dewasa disebut sebagai beranjak dewasa (emerging adulthood) yang terjadi dari usia 18 sampai 25 tahun. Pada masa ini dalam perkembangannya, banyak individu masih mengeksplorasi jalur karier yang ingin mereka ambil, ingin menjadi individu seperti apa, dan gaya hidup seperti apa yang mereka inginkan; hidup melajang, hidup bersama, atau menikah (Santrock, 2011).

Sebuah studi menunjukan bahwa bertanggung jawab sepenuhnya pada diri sendiri merupakan pertanda untuk mencapai status dewasa dan baik orang tua maupun mahasiswa setuju bahwa bertanggung jawab atas tindakan sendiri dan mengembangkan pengendalian emosi adalah aspek penting dalam proses menjadi orang dewasa (Santrock, 2011). Schulenberg, O’Malley, Bachman \& Johnston (dalam Papalia \& Feldman, 2014) menjelaskan bahwa menjadi dewasa ditandai oleh berbagai macam kemajuan, seperti: memasuki masa kuliah, bekerja, berpindah jauh dari rumah, menikah dan memiliki anak.

Ciri-ciri psikologis dari orang yang beranjak dewasa menurut Jeffrey Arnett (dalam Santrock, 2011) adalah eksplorasi identitatas dalam relasi dan pekerjaan; ketidakstabilan dalam hubungan romantis, pekerjaan dan pendidikan; terfokus pada diri sendiri dan kurang terlibat dalam kewajiban sosial dan komitmen terhadap orang lain sehingga memiliki otonomi yang besar dalam mengatur kehidupannya; merasa berada di peralihan karena tidak menganggap dirinya sebagai remaja ataupun sepenuhnya dewasa; dan usia dengan berbagai kemungkinan, di mana individu memiliki peluang untuk mengubah kehidupan mereka.

Bekerja berasal dari kata kerja yang berarti melakukan sesuatu kegiatan (Depdiknas, 2014). Pengertian bekerja secara secara sempit adalah melakukan kegiatan untuk menghasilkan sesuatu berupa uang (Jamaludin, 2016).

Dampak positif bekerja menurut Darolia (2014) adalah berpengalaman dengan dunia kerja, memiliki koneksi professional, mengembangkan soft-skill 
seperti manajemen waktu, kemampuan komunikasi dan kemampuan menyelesaikan masalah. Menurut Utomo Dananjaya (dalam Nalim, 2015) dampak positif bekerja dan berkuliah adalah mematangkan pola pikir, menumbuhkan jiwa kemandirian dan menghubungkan teori yang dipelajari dengan dunia kerja sesugguhnya dan menurut Curtis \& Shani (dalam Mardelina \& Muhson, 2017) selain keuntungan finansial, mahasiswa yang bekerja akan meningkatkan rasa percaya diri yang dimiliki.

Dampak negatif dari bekerja menurut Burke, Dolan \& Fiksenbaum (2014) adalah memiliki pengetahuan yang kurang, lebih sedikit kontak interpersonal, kurang kritis terhadap kejadian di tempat kerja, rendahnya komitmen, rendahnya kepuasan kerja, kurangnya otonomi dan kurangnya kesempatan untuk mengembangkan diri. Selain itu berkuliah dan bekerja dapat menurunkan prestasi akademik karena waktu yang dikorbankan untuk bekerja (Darolia, 2014) yang dijelaskan oleh Mardelina \& Muhson (2017) disebabkan oleh kelalaian dalam mengerjakan tugas-tugas dan kurangnya konsentrasi pada saat kegiatan belajar mengajar. Selain itu mahasiswa yang lebih menikmati kegiatan bekerja daripada kuliah akan mengesampingkan kewajiban belajarnya dan bahkan drop-out dari universitas ia mengenyam pendidikan (Mardelina \& Muhson, 2017). Bekerja juga memiliki dampak negatif seperti banyaknya waktu tersita dan kesulitan dalam membagi waktu untuk mengerjakan tugas (Audrey, 2015). Mahasiswa-mahasiswa penelitian Curtis \& Shani (dalam Greene \& Maggs, 2015) melaporkan bahwa bekerja mengganggu waktu belajar mereka dan menyebabkan mereka absen kelas, hal ini dapat menyebabkan mereka melewatkan kesempatan untuk mempelajari kemampuan yang dibutuhkan untuk sukses dalam bekerja. Mahasiswa dalam penelitian yang dilakukan oleh Richardson, Evans, \& Gbadamosi (2013) juga menyatakan bahwa mereka merasa kesulitan dalam menyeimbangkan kehidupan sosial, pekerjaan, menyelesaikan tugas tepat waktu, dan mendapatkan nilai yang baik.
Peneliti melakukan survei sederhana terhadap 31 mahasiswa di sebuah perguruan tinggi di Jakarta mengenai kegiatan yang dilakukan di luar perkuliahan dan hasilnya menunjukkan bahwa dalam satu angkatan di sebuah perguruan tinggi di Jakarta, 36,4\% mahasiswa bekerja sambil kuliah. Bekerja memiliki dampak positif bagi mahasiswa seperti mendapatkan penghasilan tambahan, melatih manajemen waktu, menambah pengalaman dan memperluas koneksi di dunia kerja (Helpster, 2017). Selain itu, mahasiswa yang bekerja juga dapat mempelajari hal baru sehingga menjadi individu yang serba bisa dan melatih keahlian yang dimiliki sebelum mendapatkan pekerjaan tetap (Andi, 2016). Berdasarkan hasil wawancara pada bulan Oktober 2017 kepada 10 mahasiswa yang bekerja, alasan lain mahasiswa bekerja adalah untuk membiayai uang kuliah mereka sendiri, belajar menjadi individu yang mandiri, mengisi waktu luang, dan memahami praktek di dunia kerja.

Berbeda dengan mahasiswa yang bekerja, mahasiswa yang tidak bekerja dapat memilih kegiatan yang mereka inginkan untuk mengisi waktu yang mereka miliki. Beberapa contoh kegiatan yang dipilih mahasiswa yang tidak bekerja berdasarkan hasil wawancara adalah bergabung dalam organisasi, berolahraga, menjadi sukarelawan dalam acara di luar perguruan tinggi dan menjadi panitia dalam acara-acara yang diadakan untuk memperingati hari khusus seperti hari kemerdekaan dan hari raya besar lainnya. Selain pilihan untuk bekerja maupun tidak bekerja, status mereka sebagai mahasiswa menuntut mereka untuk menyelesaikan tugas-tugas yang diberikan oleh dosen, mengerjakan proyek kelompok, melakukan tugas lapangan, mengikuti program magang dan belajar untuk ujian.

Berdasarkan hasil wawancara yang telah dilakukan terhadap 20 mahasiswa yang terdiri dari 10 mahasiswa bekerja dan 10 mahasiswa tidak bekerja, terdapat beberapa perbedaan dalam hambatan yang dirasakan seperti, cara menghadapi hambatanhambatan yang dialami dan kepuasan terhadap indeks prestasi kumulatif (IPK) yang telah dicapai. Hambatan-hambatan 
yang dialami mahasiswa yang bekerja terdiri dari kesulitan dalam mengatur waktu mengerjakan tugas, khususnya tugas kelompok dan kesulitan belajar karena rasa lelah setelah selesai bekerja. Mahasiswa yang tidak bekerja mengalami hambatanhambatan berupa rasa malas, kurangnya kemampuan bahasa inggris, suasana hati yang tidak menentu, lupa dengan tugas, dan kesulitan dalam menentukan prioritas mengenai kegiatan organisasi dengan mengerjakan tugas.

Mahasiswa yang bekerja dalam menghadapi hambatan-hambatan yang muncul, lebih mengandalkan diri mereka sendiri seperti: menyicil tugas saat waktu luang, memotivasi diri dan langsung mengerjakan tugas saat diberikan. Sedangkan mahasiswa yang tidak bekerja mengandalkan dirinya dan orang lain dalam menghadapi hambatan-hambatan tersebut seperti bertanya kepada dosen diluar jam perkuliahan, bertanya kepada teman yang rajin, diskusi kelompok, menandai tugas yang diberikan dan membuat jadwal untuk menyelesaikan tugas.

Hasil wawancara pada 20 mahasiswa juga menunjukkan bahwa mahasiswa yang bekerja memiliki IPK berkisar antara $2.8-3.9$, dengan 1 mahasiswa mendapat IPK 2.8 dan 9 mahasiswa mendapat IPK diatas 3, sedangkan mahasiswa yang tidak bekerja memiliki IPK berkisar antara $2.5-3.8$, dengan 3 mahasiswa mendapat IPK diatas 2 dan 7 mahasiswa mendapat IPK diatas 3 . Mahasiswa yang sukses secara akademik merasa lebih puas dan lebih terlibat dalam kampus, kepuasan mahasiswa berhubungan dengan pencapaian prestasi seperti IPK, waktu belajar, dan motivasi (Edens, Allen, \& Steen, 2016). Tetapi hasil wawancara menunjukkan bahwa mahasiswa bekerja merasa lebih puas dengan IPK yang mereka capai dibandingkan dengan mahasiswa tidak bekerja, yaitu 9 dari 10 mahasiswa bekerja merasa puas, sedangkan pada mahasiswa yang tidak bekerja hanya 3 dari 10 mahasiswa yang merasa puas dengan IPK yang mereka capai.

Dengan padatnya kegiatan perkuliahan bagi mahasiswa yang bekerja maupun tidak bekerja, mereka membutuhkan academic buoyancy dalam menjalankan keseluruhan kegiatan yang menyita waktu tersebut dan mempertahankan prestasi akademik mereka. Academic buoyancy menurut Martin \& Marsh (dalam Yu \& Martin, 2014) adalah kemampuan mahasiswa untuk berhasil melewati tantangan dan kemunduran yang menjadi bagian dari kehidupan akademik. Beberapa contoh dari academic buoyancy, seperti kemampuan untuk menghadapi performa yang buruk, memotivasi diri untuk bangkit kembali, menghadapi tekanan dan stress belajar dan berhasil menyelesaikan tugas dengan tenggat waktu yang berdekatan (Martin, Yu, Ginss, \& Papworth, 2016).

Martin \& Marsh (dalam Analya, 2014) menjelaskan 5 aspek academic buoyancy: Self-efficacy, planning, persistence, anxiety dan control. Selfefficacy adalah keyakinan siswa akan kemampuan yang mereka miliki untuk dapat menyelesaikan tugas dan ujian yang diberikan guru dengan baik dan mendapatkan hasil yang memuaskan. Planning adalah kemampuan siswa untuk menentukan target nilai yang ingin dicapai dan merencakan jadwal mengerjakan tugas dan belajar agar mencapai target nilai tersebut. Persistence adalah kegigihan siswa untuk terus mengerjakan tugas sulit yang diberikan oleh guru dan mempelajari materi yang diajarkan walaupun ada materi yang belum dipahami. Anxiety adalah kecemasan yang dialami siswa ketika menghadapi kesulitan dalam mengerjakan tugas dan mempersiapkan diri untuk menghadapi ujian. Dan sudut pandang siswa mengenai penyebab keberhasilan atau kegagalan akademik yang dialami berdasarkan faktor internal adalah aspek control.

Putwain, Daly, Chamberlain \& Sadreddini (2015) dalam penelitiannya menemukan bahwa tekanan yang lebih tinggi mengarahkan individu untuk lebih fokus pada tugas sehingga menghasilkan performa akademik yang lebih tinggi. Alasan peneliti memilih mahasiswa yang bekerja karena mahasiswa bekerja memiliki tuntutan yang lebih besar dibandingkan dengan mahasiswa tidak bekerja, yaitu 
tuntutan pekerjaan dan tuntutan akademik. Peneliti menggunakan variabel academic buoyancy sebagai tolak ukur karena academic buoyancy berlaku tidak hanya pada sebagian kecil, tetapi pada seluruh mahasiswa yang menjalani kehidupan akademik (Martin, Ginns, Brackett, Malmberg \& Hall, 2013).

Hasil penelitian Putwain, Daly, Chamberlain \& Sadreddini (2015) mendukung teori Martin \& Marsh yang menunjukkan bahwa academic buoyancy berperan dalam mempengaruhi pencapaian akademik mahasiswa, yang dalam penelitian ini ditunjukkan oleh nilai IPK mahasiswa. Penelitian-penelitian sebelumnya menunjukkan adanya perbedaan yang signifikan antara jenis kelamin dan usia, dimana perempuan memiliki academic buoyancy yang lebih tinggi daripada lakilaki dan mahasiswa yang lebih muda lebih mudah beradaptasi untuk menghadapi tantangan akademik daripada mahasiswa yang lebih tua (Martin, Yu, Ginns, \& Papworth, 2016).

Permasalahan dalam penelitian ini adalah bagaimana academic bouyancy pada mahasiswa bekerja dan tidak bekerja di Jakarta. Tujuan penelitian ini adalah untuk mengetahui academic bouyancy pada mahasiswa bekerja dan tidak bekerja di Jakarta. Penelitian ini dapat berkontribusi bagi bidang ilmu psikologi pendidikan dan dikembangan untuk penelitian lebih lanjut. Manfaat bagi mahasiswa yang bekerja dan tidak bekerja adalah informasi mengenai academic bouyancy untuk mengoptimalkan prestasi mereka. Bagi pihak perguruan tinggi dapat mengadakan kegiatan yang dapat mendukung keberhasilan akademik mahasiswa.

\section{METODE PENELITIAN}

Jenis penelitian yang digunakan adalah penelitian komparatif dengan metode kuantitatif. Penelitian komparatif yang digunakan adalah komparatif sampel independen dimana kedua kelompok yang menjadi objek penelitian dapat dipisahkan dengan jelas (Eriyanto, 2011).
Populasi dari penelitian adalah seluruh mahasiswa aktif yang berada tahap perkembangan remaja menuju dewasa, yaitu mahasiswa yang berusia 18-25 tahun, baik yang bekerja ataupun yang tidak bekerja di Jakarta. Jumlah populasi mahasiswa di Jakarta pada tahun ajaran 2016/2017 tidak diketahui. Jumlah sampel dari penelitian ini dihitung menggunakan pendekatan Isac Michel pada tingkat kepercayaan 95\% (Siregar, 2015), yaitu paling sedikit 384,16 subyek. Teknik pengambilan sampel yang digunakan adalah snowball sampling.

Metode pengumpulan data yang digunakan adalah dengan menggunakan instrument pengukuran academic buoyancy dalam bentuk kuesioner yang disusun oleh peneliti berdasarkan aspek-aspek yang dikemukakan oleh Martin \& Marsh (2010) dengan menggunakan skala sikap. Teknik analisis yang digunakan adalah uji normalitas one sample kolmogorov-smirnov test, uji perbedaan dua kelompok dilakukan dengan menggunakan independent sample ttest dengan menggunakan SPSS versi 24 dan teknik penentuan norma yang digunakan adalah dengan membandingkan rata-rata (mean) empirik dan rata-rata (mean) teoritik.

\section{HASIL DAN PEMBAHASAN}

Hasil uji normalitas menunjukkan bahwa sig 0.367 , yang berarti data penelitian ini terdistribusi normal. Hasil uji beda academic buoyancy mahasiswa bekerja dan tidak bekerja menunjukkan signifikansi 0.000 , yang menunjukkan bahwa terdapat perbedaan academic buoyancy pada mahasiswa yang bekerja dan tidak bekerja.

Uji beda academic buoyancy pada mahasiswa bekerja dan tidak bekerja juga dilakukan per aspek. Pada aspek selfefficacy menunjukkan signifikansi 0.004, yang menunjukkan bahwa terdapat perbedaan self-efficacy pada mahasiswa yang bekerja dan tidak bekerja. Pada aspek planning menunjukkan signifikansi 0.004, yang menunjukkan bahwa terdapat perbedaan planning pada mahasiswa yang bekerja dan tidak bekerja. Pada aspek persistence menunjukkan signifikansi 0.004, yang menunjukkan bahwa terdapat 
perbedaan persistence pada mahasiswa yang bekerja dan tidak bekerja. Pada aspek anxiety menunjukkan signifikansi 0.000, yang menunjukkan bahwa terdapat perbedaan anxiety pada mahasiswa yang bekerja dan tidak bekerja. Dan pada aspek control menunjukkan signifikansi 0.114 , yang menunjukkan bahwa tidak terdapat perbedaan control pada mahasiswa yang bekerja dan tidak bekerja.

Hasil uji beda academic buoyancy terhadap jenis kelamin mahasiswa bekerja dan tidak bekerja menunjukkan signifikansi 0.816 untuk mahasiswa bekerja dan 0.705 untuk mahasiswa tidak bekerja yang menunjukkan bahwa tidak terdapat terdapat perbedaan academic buoyancy terhadap jenis kelamin, baik pada mahasiswa bekerja maupun tidak bekerja.

Hasil uji beda academic buoyancy terhadap kepuasan IPK mahasiswa bekerja dan tidak bekerja menunjukkan signifikansi 0.111 untuk mahasiswa bekerja dan 0.000 untuk mahasiswa tidak bekerja yang menunjukkan bahwa tidak terdapat terdapat perbedaan academic buoyancy terhadap IPK mahasiswa bekerja tetapi terdapat perbedaan terhadap IPK mahasiswa tidak bekerja.

Norma academic buoyancy secara keseluruhan menunjukkan bahwa mahasiswa bekerja dan tidak bekerja memiliki academic buoyancy yang tinggi dengan nilai rata-rata 2.71 pada mahasiswa bekerja dan nilai rata-rata 2.55 pada mahasiswa tidak bekerja.

Pengkategorian norma per aspek menunjukkan bahwa mahasiswa bekerja dan tidak bekerja memiliki nilai yang tinggi pada aspek self-efficacy, planning, persistence dan control, dengan nilai rata-rata selfefficacy 2.79 dan 2.66, aspek planning dengan nilai rata-rata 2.69 dan 2.53 , aspek persistence dengan nilai rata-rata 2.87 dan 2.72, dan aspek control dengan nilai ratarata 2.86 dan 2.77. Sedangkan keduanya memiliki nilai yang cenderung rendah pada aspek anxiety dengan nilai rata-rata 2.36 dan 2.15 .

Hasil penelitian menunjukkan bahwa terdapat perbedaan academic buoyancy pada mahasiswa bekerja dan tidak bekerja. Putwain, Daly, Chamberlain \&
Sadreddini (2015) dalam penelitiannya menemukan bahwa tekanan yang lebih tinggi mengarahkan individu untuk lebih fokus pada tugas sehingga menghasilkan performa akademik yang lebih tinggi. Perbedaan academic buoyancy mahasiswa bekerja dan tidak bekerja dipengaruhi oleh tekanan yang mereka rasakan, di mana mahasiswa bekerja mengalami tekanan kerja di luar dari tekanan akademik, yang menyebabkan mahasiswa bekerja lebih fokus untuk menyelesaikan tugas dan tanggung jawab yang diberikan pada mereka, baik dari tempat kerja maupun dari universitas.

Perhitungan uji beda academic buoyancy per aspek menunjukkan bahwa terdapat perbedaan pada aspek self-efficacy $(0.004<0.05)$ pada mahasiswa bekerja dan tidak bekerja. Bandura (dalam Trujillo \& Tanner, 2014) menyatakan bahwa lebih mudah mempertahankan self-efficacy ketika menghadapi kesulitan apabila orang lain mempercayai kemampuan yang kita miliki. Mahasiswa yang bekerja maupun tidak bekerja mendapatkan pengakuan akan kemampuan yang dimiliki dari temantemannya ketika menghadapi kesulitan akademik yang dialami (Cassidy, 2015). Penelitian lintas budaya yang dilakukan oleh Luszczynska et al. menunjukkan bahwa terdapat hubungan positif antara selfefficacy dengan kepuasan akademik, kepuasan jurusan dan kepuasan sosial (Azizli, Atkinson, Baughman \& Giammarco, 2015). Sejalan dengan penelitian tersebut, perbedaan nilai rata-rata mahasiswa bekerja yang lebih tinggi disebabkan karena kepuasan akademik yang mereka rasakan, yang dibuktikan dengan kepuasan terhadap IPK yang telah mereka capai.

Perhitungan uji beda academic buoyancy per aspek juga menunjukkan adanya perbedaan pada aspek planning $(0.004<0.05)$ pada mahasiswa bekerja dan tidak bekerja dikarenakan mahasiswa bekerja harus merencanakan kegiatan mereka, seperti belajar, mengerjakan tugas dan bekerja agar dapat menyeimbangkan kehidupan mereka sebagai mahasiswa dan pekerja. Hal tersebut juga didukung oleh 
dampak positif dari bekerja, yaitu pengembangan soft-skill seperti manajemen waktu (Darolia, 2014).

Hasil perhitungan uji beda aspek persistence juga menunjukkan adanya perbedaan kegigihan $(0.004<0.05)$ pada mahasiswa bekerja dan tidak bekerja. Ishler dkk. (dalam Kennel \& Smith, 2017) menyatakan bahwa persistence dipengaruhi oleh persiapan, kemampuan dan motivasi. Mahasiswa yang mengikuti kegiatan di luar perkuliahan, baik bekerja maupun tidak bekerja melakukan kegiatan tersebut atas keinginan mereka sendiri (motivasi), yang membedakan adalah persiapan yang mereka lakukan untuk menjalankan kegiatan tersebut dan kemampuan untuk menyeimbangkan kehidupan di dalam dan luar perkuliahan. Penelitian yang dilakukan oleh Burrus et al. (2013) menunjukkan bahwa pengalaman di luar perkuliahan berpengaruh lebih pada persistence dibandingkan latar belakang, komitmen dan keinginan untuk lulus.

Hasil perhitungan uji beda aspek anxiety juga menunjukkan adanya perbedaan kecemasan $(0.000<0.05)$ pada mahasiswa bekerja dan tidak bekerja. Goh (dalam Bayat, Jamshidipour \& Hashemi, 2017) menyatakan bahwa mahasiswa cemas akan membuat kesalahan dan takut mendapatkan evaluasi negatif. Mahasiswa bekerja maupun tidak bekerja memiliki kecemasan akan membuat kesalahan dalam belajar maupun saat melakukan kegiatan di luar kelas tetapi bagi mahasiswa bekerja, tanggung jawab di tempat kerja yang harus diselesaikan dengan baik menambah kecemasan yang mereka alami.

Penelitian-penelitian sebelumnya menunjukkan bahwa dukungan akademik, usaha akademik dan self-efficacy berkorelasi negatif dengan kecemasan mahasiswa (Maharajan Rajiah, Tam, Chaw, Ang, \& Yong. 2017). Mahasiswa yang bekerja mendapatkan lebih sedikit dukungan akademik dari teman-teman maupun pengajar karena waktu yang mereka habiskan untuk bekerja, sedangkan mahasiwa yang tidak bekerja, baik berorganisasi maupun tidak melakukan kegiatan apapun menghabiskan lebih banyak waktu di lingkungan perkuliahan yang memudahkan mereka untuk mencari dukungan akademik dari teman-teman maupun pengajar.

Perhitungan uji beda menunjukkan bahwa tidak terdapat perbedaan pada aspek control $(0.114<0.05)$. Hasil penelitian yang dilakukan oleh Collie, Martin, Malmberg, Hall \& Ginns (2014) menyatakan bahwa control merupakan penghubung academic buoyancy dengan prestasi mahasiswa. Wiener (dalam Collie, Martin, Malmberg, Hall \& Ginns, 2014) menyatakan bahwa mahasiswa yang melihat penyebab dari tantangan akademik yang mereka alami berdasarkan faktor internal akan mengubah perilaku agar tidak mengulangi hasil yang sama di masa depan. Baik mahasiswa bekerja maupun tidak bekerja memandang bahwa prestasi yang mereka capai merupakan hasil belajar mereka (faktor internal), sehingga hasil uji beda menunjukkan tidak adanya perbedaan pada aspek control.

\section{SIMPULAN}

Dari penjabaran di atas, dapat disimpulkan bahwa terdapat perbedaan academic buoyancy pada mahasiswa bekerja dan mahasiswa tidak bekerja khususnya pada aspek self-efficacy, planning, persistence dan anxiety, tetapi tidak terdapat perbedaan pada aspek control. Meskipun demikian, baik mahasiswa bekerja maupun mahasiswa tidak bekerja berada pada kategori yang sama pada setiap aspeknya, perbedaan keduanya terletak pada nilai ratarata yang dimiliki, di mana mahasiswa bekerja memiliki nilai rata-rata lebih tinggi untuk kelima aspek academic buoyancy.

Saran teoritis bagi bidang ilmu psikologi pendidikan yaitu memperkaya kajian ilmu psikologi pendidikan di Indonesia dengan adanya penelitianpenelitian mengenai academic buoyancy pada mahasiswa dan bagi penelitian selanjutnya yaitu agar memperketat kontrol sampel seperti sosiodemografik, pendidikan orang tua dan status sosial ekonomi orang tua untuk mengurangi bias dengan variabel resiliensi akademik, memperkaya penelitian 
academic buoyancy pada mahasiswa dengan memasangkan variabel-variabel berbeda seperti, perspektif waktu dan dilakukan penelitian menggunakan metode penelitian campuran (mix method) agar mendapatkan hasil yang lebih mendalam.

Saran praktis bagi mahasiswa yang bekerja setelah mengetahui academic buoyancy yang dimiliki yaitu mengurangi kecemasan yang dirasakan dengan menyisihkan beberapa menit setiap hari untuk menenangkan diri dan membuat skala prioritas untuk menyelesaikan hal yang penting dan mendesak terlebih dahulu, bagi mahasiswa yang tidak bekerja diharapkan untuk membuat rencana belajar dengan detil dan membuat target nilai yang sesuai dengan kemampuan diri sendiri. Saran bagi pihak perguruan tinggi setelah mengetahui academic buoyancy yang dimiliki oleh mahasiswa yaitu membuat sistem pembelajaran yang dapat mendukung keberhasilan mahasiswa dalam hal akademik seperti pembelajaran yang lebih menekankan pada praktek tidak hanya teori dan mengadakan kegiatan non-akademik seperti lomba-lomba internal dan eksternal, pelatihan softskill, dan memfasilitasi komunitas-komunitas yang mendukung pengembangan diri untuk menanamkan sikap-sikap yang dapat mendukung keberhasilan akademik.

\section{DAFTAR PUSTAKA}

Agustina, S. (2014, November).Menyiasati beratnya hidup di Ibukota Jakarta. Diunduh dari http://megapolitan.kompas.com/read/ 2014/11/19/14000071/Menyiasati.Be ratnya.Hidup.di.Ibu.Kota.Jakarta

Analya, P. (2014). Studi deskriptif mengenai derajat academic buoyancy pada siswa kelas XII di SMA ' $X$ ' Bandung. Jurnal Psikologi Humanitas, 1(1), 4554.

Andi. (2016, Febuari). Kerja part time. Diunduh

darihttp://www.ruangfreelance.com/k erja-part-time/

Audrey, M. (2015, September). Kuliah sambil bekerja, mungkin nggak ya?.
Diunduh

dari

http://ipk.sinarharapan.co/ipk/read/15

0929100/kuliah-sambil-bekerja-

mungkin-nggak-ya-

Azizli, N., Atkinson, B. E., Baughman, H. M., \& Giammarco, E. A. (2015). Relationships between general selfefficacy, planning for the future, and life satisfaction. Personality and Individual Differences, 82, 58-60.

Bayat, A., Jamshidipour, A., \& Hashemi, M. (2017). The beneficial impacts of applying formative assessment on Iranian university students' anxiety reduction and listening efficacy. International Journal of Languages, Education and Teaching, 5(2), 1-11. DOI: 10.18298/ijlet.1740

Burke, R. J., Dolan, S. L., \& Fiksenbaum, L. (2014). Part-time versus full-time work: Empirical evidence-based case of nurses in Spain. Evidence-based HRM: A Global Forum for Empirical Scholarship, 2(2), 176-191.

Burrus, J., Elliot, D., Brenneman, M., Markle, R., Carney, L., Moore, G., Roberts, R. D. (2013). Putting and keeping students on track: Toward a comprehensive model of college persistence and goal attainment (Research Report). Diunduh dari https://www.ets.org/Media/Research/ pdf/RR-13-14.pdf.

Cassidy, S. (2015). Reilience building in students: The role of academic selfefficacy. Frontiers in Psychology. Diunduh dari https://www.frontiersin.org/articles/1 0.3389/fpsyg.2015.01781/full.

Collie, R. J., Martin, A. J., Malmberg, L. E., Hall, J., Ginns, P. (2014). Academic buoyancy, student achievement, and the linking role of control: A crosslagged analysis of high school students. The British Journal of Educational Psychology, 85 (1). DOI: 10.1111/bjep.12066.

Darolia, R. (2014). Working (and studying) day and night: Heterogeneous effects of working on the academic performance of full-time and part- 
time students. Economic of Education Review, 38, 38-50.

Depdiknas. (2014). Kamus Besar Bahasa Indonesia (edisi keempat). Jakarta: Gramedia Pustaka Utama.

Edens, D., Allen, M., \& Steen, J. (2016). Academic satisfaction of Latino students: Differences and predictors. Journal of Education and Training, 3(2), 46-63. DOI:10.5296/jet.v3i2.9400.

Erasiana. (2017, Maret). Apa itu pekerjaan paruh waktu (part time) serta kelebihannya. Diunduh dari http://www.erasiana.com/apa-itupekerjaan-paruh-waktu-part-timeserta-kelebihannya.html

Eriyanto. (2011). Analisis isi: Pengantar metodologi untuk penelitian ilmu komunikasi dan ilmu-ilmu sosial lainnya. Prenada Media Group: Jakarta

Goodwin, C. J. (2010). Research in psychology: Methods and design (6 $6^{\text {th }}$ ed.). USA: John Wiley \& Sons, Inc.

Gravetter, F. J., \& Forzano, L. A. B. (2012). Research methods for the behavioral sciences $\left(4^{\text {th }}\right.$ ed.). Canada: Cengage Learning.

Gravetter, F. J., \& Wallnau, L. B. (2017). Statistics for the behavioral science $\left(10^{\text {th }}\right.$ ed.). USA: Cengage Learning.

Greene, K. M. \& Maggs, J. L. (2015). Revisiting the time trade-off hypothesis: Work, organized activities and academic during college. Journal Youth Adolescence, 44(8), 1623-1637. Diunduh dari https://www.ncbi.nlm.nih.gov/pmc/ar ticles/PMC4426080/

Helpster. (2017, Juli). 4 keuntungan bekerja part time. Diunduh darihttps://www.helpster.asia/id/keun tungan-bekerja-part-time/

Iswahyudi, S. (2015, Mei). Kerja di Jakarta Ternyata Engga Bikin tidur nyenyak?. Diunduh dari http://careernews.id/youknow/view/3 313-Kerja-di-Jakarta-TernyataEnggak-Bikin-Tidur-Nyenyak
Jamaludian, A. (2016). Perbandingan hasil belajar antara mahasiswa yang bekerja dengan yang tidak bekerja pada matakuliah ekonomi mikro di STIE YPBI Jakarta. Jurnal Administrasi Kantor, 4(1): 198-210.

Kelembagaan Ristekdikti. (n.d). Undangundang Republik Indonesia nomor 12 tahun 2012 tentang pendidikan tinggi. Diunduh dari http://kelembagaan.ristekdikti.go.id/i ndex.php/undang-undang/

Kennel, K. D. \& Smith, P. W. (2017). Academic persistence among nursing students: A concept analysis. Journal of Nursing Education and Practice, $7(11)$.

Maharajan, M. K., Rajiah, K., Tam, A. M., Chaw, S. L. Ang, M. J., \& Yong, M. W. (2017). Pharmacy students' anxiety towards research during their undergraduate degree; How to reduce it?. Research Article. Diunduh dari http://journals.plos.org/plosone/articl e?id=10.1371/journal.pone.0176095

Mardelina, E., \& Muhson, A. (2017).Mahasiswa bekerja dan dampaknya pada aktivitas belajar dan prestasi akademik. Jurnal Economia, 13(2).

Martin, A. J., Colmar, S.H., Davey, L.A., \& Marsh, H.W. (2010). Longitudinal modeling of academic buoyancy and motivation: Do the '5Cs' hold up over time? British Journal of Educational Psychology, 80, 473-496. DOI: 10.1348/000709910X486376.

Martin, A. J., Ginns, P., Brackett, M. A., Malmberg, L. E., \& Hall, J. (2013). Academic buoyancy and psychological risk: Exploring reciprocal relationships. Learning and Individual Differences, 27, 128-133. DOI: 10.1016/j.lindif.2013.06.006.

Martin, A. J., Yu, K., Ginns, P., \& Papworth, B. (2016). Young people's academic buoyancy and adaptability: A crosscultural comparison of China with North America and the United Kingdom. Educational Psychology. DOI: 10.1080/01443410.2016.1202904. 
Mohamad, A. (2012, Juli). Sarjana Indonesia terbanyak kelima di dunia. Diunduh dari https://www.merdeka.com/dunia/sarj ana-indonesia-terbanyak-kelima-didunia.html

Nalim, N. (2015). Analisis faktor yang mempengaruhi motivasi belajar mahasiswa yang kuliah sambil bekerja. Jurnal Ilmiah Kependidikan Khasanah Pendidikan, 7(2). DOI: 10.30595/jkp.v8i2.675.

Noor, J. (2011). Metodologi penelitian: Skripsi, tesis, disertasi, dan karya ilmiah (edisi 1). Jakarta: Prenada Media.

Papalia, D. E. \& Feldman, R.D. (2014). Menyelami perkembangan manusia jilid 2 (Edisi Keduabelas). Jakarta: Salemba Humanika.

Pendidikan tinggi masih penting di bursa kerja. (2013, Januari). Diunduh dari https://www.bbc.com/indonesia/maja lah/2013/01/130110_pendidikan_gel ar_universitas

Putwain, D. W., Daly, A. L., Chamberlain, S., \& Sadreddini, S. (2015). "Sink or swim": Buoyancy and coping in the cognitive test anxiety - academic performacen relationship. $A n$ International Journal of Experimental Educational Psychology, 36(10), 1807-1825.

Ruane, J. M. (2013). Dasar-dasar metode penelitian: Panduan riset ilmu sosial. Bandung: Penerbit Nusa Media.

Richardson, M., Evans, C., Gbadmosi, G. (2013). Academic plate spinning: The difficulties of balancing full time degree study with a part-time job. Worcester Journal of Learning and Teaching, (8). ISSN 2024-8032.

Santrock, J. W. (2011). Life-span development (perkembangan masahidup) jilid 2 (Edisi Ketigabelas). Jakarta: Erlangga.

Siregar, S. (2015). Metode penelitian kuantitatif: Dilengkapi perbandingan perhitungan manual \& SPSS (Edisi pertama). Jakarta: Prenamedia Group.

Sutriyanto, E. (2012, September). Kesadaran generasi muda terhadap pendidikan meningkat. Diunduh dari http://www.tribunnews.com/bisnis/20 12/09/07/kesadaran-generasi-mudaterhadap-pendidikan-meningkat

Syaaf, S., \& Wibawa, S. W. (2017, April). Hidup di Jakarta dengan gaji Rp 3 juta, cukup atau kurang?. Diunduh dari

http://lifestyle.kompas.com/read/201 7/04/28/110200120/hidup.di.jakarta. denga

Tarbetsky, A. L., Martin, A. J., \& Collie, R. J. (2017). Social and emotional learning, social and emotional competence and students' academic outcomes: The roles of psychological need satisfaction, adaptability, and buoyancy. Social and emotional learning in Australia and the Asia Pacific.

Trujillo, G., \& Tanner, K. D. (2014). Considering the role of affect in learning: Monitoring students' selfefficacy, sense of belonging and science identity. CBE Life Sciences Education, 13(1), 6-15. Diunduh dari https://www.ncbi.nlm.nih.gov/pmc/ar ticles/PMC3940464/

Yu, K., \& Martin, A.J. (2014). Personal best (PB) and 'classic' achievement goals in the Chinese context: Their role in predicting academic motivation, engagement, and buoyancy. Educational Psychology: An International Journal of Experimental Educational Psychology, 34, 635-658. DOI: 10.1080/01443410.2014.895297

Zamhari. (2016, Juli). Apa itu mahasiswa? Inilah pengertian mahasiswa yang jarang anda ketahui hingga saat ini. Diunduh dari http://www.academicindonesia.com/ pengertian-mahasiswa/ 